\title{
A Cost Comparison of Fuel-Cell and Battery Electric Vehicles
}

\author{
Stephen Eaves ", James Eaves \\ Eaves Devices, Charlestown, RI, Arizona State University-East, Mesa, AZ
}

\begin{abstract}
This paper compares the manufacturing and refueling costs of a Fuel-Cell Vehicle (FCV) and a Battery Electric Vehicle (BEV) using an automobile model reflecting the largest segment of light-duty vehicles. We use results from widely-cited government studies to compare the manufacturing and refueling costs of a BEV and a FCV capable of delivering 135 horsepower and driving approximately 300 miles. Our results show that a BEV performs far more favorably in terms of cost, energy efficiency, weight, and volume. The differences are particularly dramatic when we assume that energy is derived from renewable resources.
\end{abstract}

Keywords: Battery-Electric Vehicle; Fuel-Cell Vehicle; Well-to-Wheel; Energy Pathway

\section{Introduction}

Both the federal and state governments have enacted legislation designed to promote the eventual widespread adoption of zero-emissions vehicles. For instance, California enacted the Zero-Emissions-Vehicle (ZEV) program mandating automakers to claim ZEV credits for a small percentage of total vehicle sales starting in 2003. Further, the last version of the 2003 energy bill included over a billion dollars in incentives for automakers to develop technology related to Fuel-Cell Vehicles. Currently, the Fuel-Cell Vehicle (FCV) and the Battery Electric Vehicle (BEV) are the only potential ZEV replacements of the internal combustion engine, however, no studies have directly compared the two technologies in terms of performance and cost when considering the most recent advances in battery and fuel-cell technology. Below, we compare BEV and FCV technologies based on a vehicle model that is capable of delivering $100 \mathrm{~kW}$ of peak power, and $60 \mathrm{kWh}$ total energy to the wheels..$^{1}$ This translates into a vehicle that is capable of delivering 135 horsepower and driving approximately 300 miles. The vehicle characteristics are comparable to a small to midsize car, such as a Honda Civic, representing the largest segment of the light-duty vehicle class [1].

We first compare the relative efficiency of the vehicles' well-to-wheel pathways. This allows us to calculate the amount of energy a power plant must produce in order to deliver a unit of energy to the wheels of a FCV and a BEV. Next, we compute the volume, weight, and refueling costs associated with each vehicle. We make these calculations first assuming that the hydrogen for the FCVs and the electricity

\footnotetext{
${ }^{*}$ Corresponding author. Tel.: 401-315-0547; E-mail: stepheneaves@eavesdevices.com
} 
for the BEVs are generated using nonfossil fuel sources. After, we relax this assumption to consider the case where hydrogen is reformed from natural gas and the electricity for BEVs is generated using a mix of fossil fuel and non-fossil fuel sources, such as wind and hydroelectric, as is the norm today.

\section{Analysis and Discussion}

\subsection{Energy Efficiency Comparison assuming energy is derived from renewable resources}

A vehicle's well-to-wheel pathway is the pathway between the original source of energy (e.g. a wind farm) and the wheels of the car. The pathway's components are the energy conversion, distribution, and storage stages required to transport and convert the energy that eventually moves the automobile. Thus, analyzing the efficiency of each vehicle's well-to-wheel pathway allows us to determine the total amount of energy required to move each vehicle.

Fig. 1 and Fig. 2 illustrate the pathways for BEVs and FCVs, respectively. The first stage of both pathways is the generation of electricity. Since presumably we are concerned with the long-run development of a sustainable transportation infrastructure, we first assume that the electricity is generated by a non-fossil fuel resource like hydroelectric, solar, wind, geothermal, or a combination. All of these sources are used to generate energy in the form of electricity. The only established method to convert electricity to hydrogen is through a process known as electrolysis, which electrically separates water into its components of hydrogen and oxygen.

For BEVs, the electricity is delivered over power lines to a battery charger. The battery charger then charges a Lithium-ion battery that stores the energy on-board the vehicle to power the vehicle's drivetrain. In addition to one storage and two distribution stages, the BEV pathway consists of two conversion stages (the conversion of, say, wind to electricity in stage 1 and the conversion of electricity to mechanical energy in stage 2). The figure shows that the entire pathway is $77 \%$ efficient; approximately $79 \mathrm{kWh}$ of energy must be generated in order to deliver the necessary $60 \mathrm{kWh}$ of electricity to the wheels of the car.

The FCV's well-to-wheel pathway, illustrated in Fig. 2, is believed by experts to be the most likely scenario, with some exceptions that are addressed below [2]. In this case, the energy from the electric plant is used for the electrolysis process that separates hydrogen gas from water. The hydrogen gas is then compressed and distributed to fueling stations where it can be pumped into and stored aboard individual fuel-cell vehicles. The onboard hydrogen gas is then combined with oxygen from the atmosphere to produce the electricity that powers the vehicle's drivetrain. 


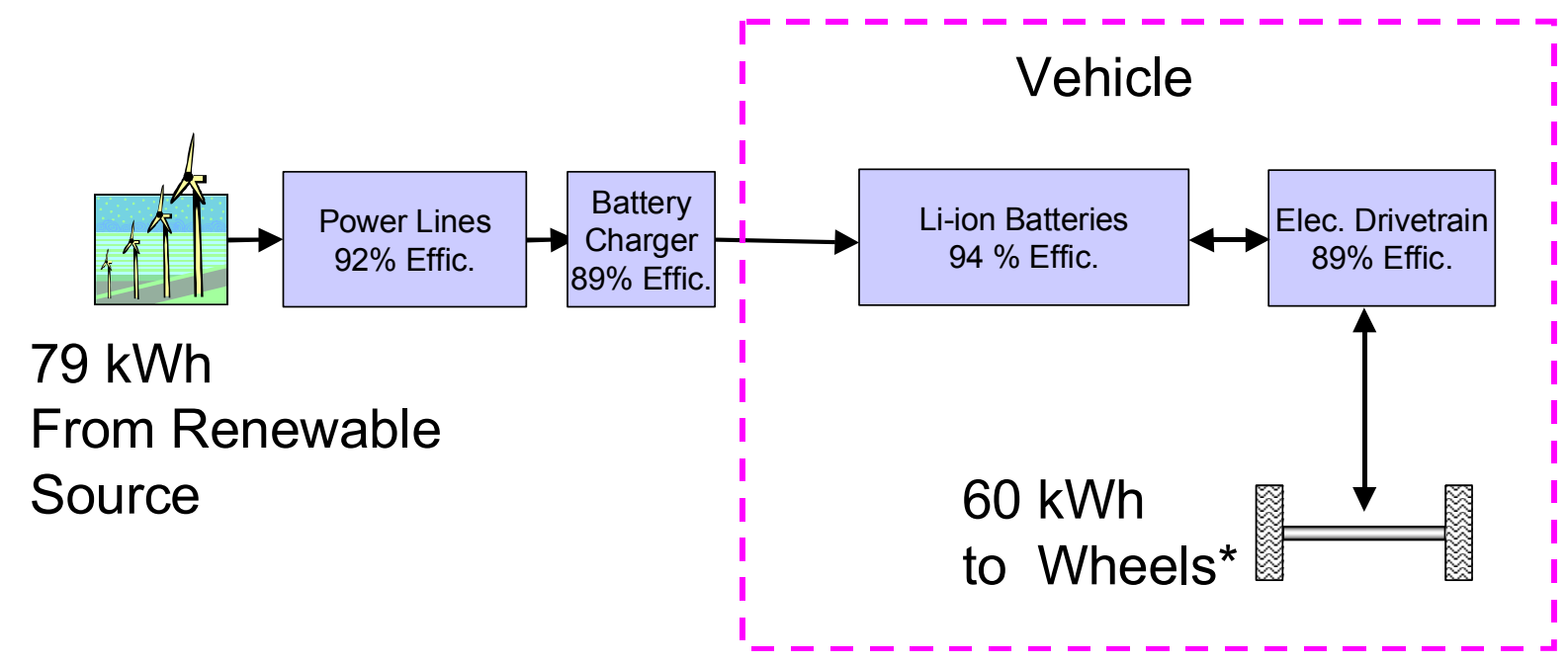

${ }^{*} T$ The BEV regeneration capability reduces the $60 \mathrm{kWh}$ requirement by $6 \mathrm{kWh}$ while achieving the same range

Fig. 1 - Well-to-Wheel Energy Pathway for Battery Electric Vehicle

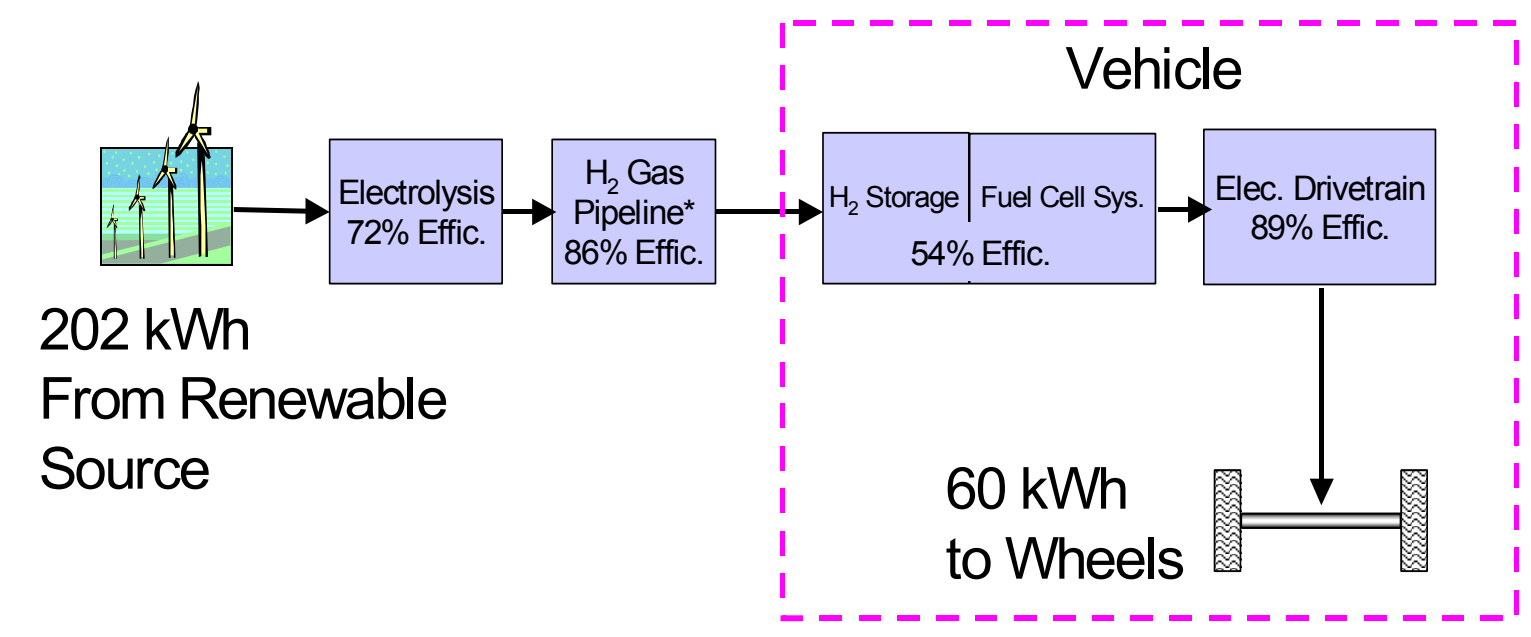

* "Pipeline" includes losses from compression, expansion, storage and distribution

Fig. 2 - Well-to-Wheel Energy Pathway for Fuel Cell Vehicle 
In addition to one distribution and one storage stage, the FCV pathway consists of four conversion stages (the conversion of, say, wind to electricity in stage 1 , the conversion of electricity to hydrogen in stage 2 , the conversion of hydrogen back to electricity in stage 3 , and finally, the conversion of electricity to mechanical energy in stage 4). Due largely to the fact that there are two additional conversion stages relative to the $\mathrm{BEV}$ and the fact that the onboard conversion stage is only $54 \%$ efficient, the FCV pathway is only approximately $30 \%$ efficient..$^{\underline{3}}$ The result is that the pathway requires the production of $202 \mathrm{kWh}$ of electricity at the plant, to deliver the necessary $60 \mathrm{kWh}$ to the vehicle, or 2.6 times the requirements of the $\mathrm{BEV}$ pathway [3]. Obviously, this means that there would need to be 2.6 times as many wind farms or solar panels to power the FCVs versus the BEVs.

Arguably, a more efficient FCV pathway would be based on-board fossil fuel reforming or liquid hydrogen storage. However, attempts at these alternative methods have proven uncompetitive compared to a system based on compressed hydrogen gas. As a consequence, the pathway illustrated in Fig. 2 is considered by the DOE and industrial experts to be the most feasible [2].

However, contrary to our present assumption, the DOE's support for the distribution pipeline of Fig. 2 is based on the assumption of initially using fossil fuels as the source of hydrogen. In the case of renewable energy, it would be more cost effective to transport the electricity over power lines and perform the electrolysis at local "gas stations", thus eliminating the need for the expensive and less efficient hydrogen pipeline [4]. Elimination of the hydrogen pipeline stage significantly increases the overall efficiency of the pathway, however, $188 \mathrm{kWh}$ is still necessary to deliver $60 \mathrm{kWh}$ to the FCV's wheels, or 2.4 times the energy required to power a $\mathrm{BEV}$.

The results of the non-fossil fuel analysis are impacted by the fact that we do not consider the cost of constructing and maintaining a hydrogen infrastructure. A renewable hydrogen infrastructure would consist of a network of electrolysis plants, supported by an intra-national pipeline, which, in turn, would supply a myriad of hydrogen refueling stations. The cost of hydrogen production from electrolysis is already well characterized from existing installations, but accurately projecting the downstream costs of a massive transportation and distribution infrastructure is much more difficult. The practical implication of only considering the production costs is that our estimate of the FCV's refueling cost is lower than it would be if we considered infrastructure costs. For instance, the cost of building the hydrogen refueling stations alone is estimated between $\$ 100$ billion and $\$ 600$ billion.[5] The U.S. Department of Energy estimates the costs of the hydrogen trunk pipelines and distribution lines to be $\$ 1.4$ million and $\$ 0.6$ million per mile, respectively[6]. A BEV infrastructure would be largely based on the current power grid, making its construction vastly less costly. ${ }^{-}$

The inefficiency of the FCV pathway combined with the high capital and maintenance costs of the distribution system results in significant differences in the refueling cost between a FCV and $\mathrm{BEV}$, particularly if the source is 
renewable. For example, Pedro and Putsche [7] estimate that using wind energy, hydrogen production costs alone will amount to $\$ 20.76$ per tank to drive our FCV 300 miles compared to $\$ 4.28$ "per tank" (or per charge) for the BEV..$^{4}$

\subsection{Comparison of Weight, Volume and Cost}

Maintaining the same performance assumptions, we next compare the projected relative weight, volume, and unit costs of each vehicles propulsion system. The results are reported in Table 1 and Table 2. When interpreting the tables it is important to note that the limiting factor in FCV performance is the amount of power that can be delivered, which affects vehicle acceleration and hill climbing. For BEVs, the limiting factor is the amount of energy that can be delivered, which affects total vehicle range. This means that the scaling factors for weight, volume, and cost for the FCV are based on how many Watts (of power) that can be delivered per unit of weight, volume, or cost. For the BEV it is the amount of Watt-hours (of energy) that can be delivered per unit of weight, volume, or cost.

Table 1

Estimated weight, on-board space, and mass-production cost requirements of the FCV propulsion system

\begin{tabular}{lllll}
\hline Component & Weight & Volume & Cost & Reference \\
\hline Fuel-Cell & $617 \mathrm{~kg}$ & 1182 liters & $\$ 23,033$ & ADL(2001) \\
$3.2 \mathrm{~kg}$ storage tank & $51 \mathrm{~kg}$ & 215 liters & $\$ 2,288$ & $\begin{array}{l}\text { Padro and } \\
\text { Putsch(1999) } \\
\text { Drivetrain }\end{array}$ \\
& $53 \mathrm{~kg}$ & 68 liters & $\$ 3,826$ & $\begin{array}{l}\text { AC Propulsion, } \\
\text { Inc.(2001), Solectria } \\
\text { Corp (2001) }\end{array}$ \\
& & & & \\
\hline
\end{tabular}

Table 2

Estimated weight, on-board space, and mass-production cost requirements of a BEV propulsion systems

\begin{tabular}{lllll}
\hline Component & Weight & Volume & Cost & Reference \\
\hline Li-ion Battery & $451 \mathrm{~kg}$ & 401 liters & $\$ 16,125$ & $\begin{array}{l}\text { Gaines and } \\
\text { Cuenca(2000) }\end{array}$ \\
Drivetrain & $53 \mathrm{~kg}$ & 68 liters & $\$ 3,826$ & $\begin{array}{l}\text { Cuenca and Gains } \\
(1999)\end{array}$ \\
Total & $\mathbf{5 0 4} \mathbf{~ k g}$ & $\mathbf{4 6 9}$ liters & $\mathbf{\$ 1 9 , 9 5 1}$ & \\
\hline
\end{tabular}




\subsection{Weight Comparison}

According to the DOE report on the status of fuel-cells conducted by Arthur D. Little [8], a modern fuel cell is presently capable of delivering 182 Watts of power per $\mathrm{kg}$ of fuel-cell. Including the required FCV drivetrain components and their losses $[9,10]$ and the weight of the storage $\operatorname{tank}^{\underline{5}}$, a fuel-cell propulsion system capable of meeting our performance constraint must weigh approximately $721 \mathrm{~kg}$. According to the National Renewable Energy Laboratory (NREL) working group report on advanced battery readiness [11], a Lithium-ion battery is capable of delivering 143 Watts.hours of energy per $\mathrm{kg}$ of battery. Considering an equivalent drivetrain to the one assumed for the FCV, the battery system must weigh 504 $\mathrm{kg}$ to satisfy our performance constraint. $\underline{6}$

\subsection{Volume Comparison}

The Arthur D. Little study reports that the fuel-cell delivers 95 Watts per liter of fuel-cell, which combined with the volume of the hydrogen storage tank [12] and the volume of the electric drivetrain components produces a total volume of 1465 liters. $^{\text {? }}$ A Lithium-ion battery delivers 161 Watt-hours per liter of battery. ${ }^{-}$When combined with the electric drivetrain volume, this results in a total volume of 469 liters.

\subsection{Cost Comparison}

Finally, The Arthur D. Little study reports a cost of $\$ 205$ per $\mathrm{kW}$ for a $100 \mathrm{~kW}$ fuel-cell. ${ }^{9}$ Adding to this the cost of the electric motor, control electronics and hydrogen-storage tank implies that the total cost of $\$ 29,147$ for the fuel-cell propulsion system(The electric drivetrain components are $\$ 3,826$ for the BEV and FCV.) [13]. For the BEV, the cost of a Lithium-ion battery is estimated to be $\$ 250 / \mathrm{kWh}$ [14]. Considering the electric drivetrain, this implies a total cost of $\$ 19,951$ for the BEV's propulsion system.

\subsection{Energy Efficiency Comparison assuming energy is derived from Fossil Fuels}

Most experts are imagining that for many years to come, fossil fuels will be the main source of the hydrogen or the electricity that powers zero emission vehicles. In light of this, one should consider the near term case where the electricity for BEVs is generated using a mix of fossil fuel and non-fossil fuel sources and the FCV's hydrogen is reformed from natural gas, as is the norm today.

A 2001 study conducted for the California Air Resources Board found that when electricity for BEVs is generated using a mix of fossil fuel and non-fossil fuel and hydrogen is created from natural gas, a $\mathrm{BEV}$ pathway is about $8 \%$ more efficient than a FCV pathway. The study also concluded that the BEV pathway would generate lower greenhouse gas emissions. Although the efficiency comparison of the two vehicles is much closer than for the non-fossil fuel case, if the substantial cost of building and maintaining the hydrogen infrastructure necessary to support the FCV is considered, then the BEV would clearly be more attractive than the FCV. Further, if renewable energy sources will eventually replace fossil fuels, then the hydrogen pipeline would at best be inefficient, and at worst be obsolete. 
This is because hydrogen producers would find it more economical to make hydrogen locally by using renewable electricity to hydrolyze water, rather than purchasing hydrogen transported via pipeline. Since the nation's electricity is already generated using an array of fossil and non-fossil fuel resources, the optimal design of the BEV infrastructure would not change in the conversion to a nonfossil fuel economy.

Lastly, when the non-fossil fuel assumption is relaxed, the refueling cost of a BEV is still far less than that of the FCV. Pedro and Putsch estimate the retail cost of hydrogen from fossil fuel to be $\$ 2.42$ per $\mathrm{kg}$ [7]. Given the $3.2 \mathrm{~kg}$ of hydrogen necessary to meet our rangeperformance constraint, this results in a fill-up cost of $\$ 7.77$ for the FCV.

Accounting for efficiency losses between a BEV's battery and its wheels, $64.5 \mathrm{kWh}$ of energy must be delivered to the BEV battery to assure that $60 \mathrm{kWh}$ is delivered to its wheels. Considering a 0.89 charger efficiency and a 0.94 battery efficiency, this implies that $77 \mathrm{kWh}$ of energy must be purchased from the utility company. Since BEVs will typically be charged at night, an off-peak cost of $\$ 0.06 / \mathrm{kWh}$ is applied for the electricity generated from a mix of fossil and nonfossil fuels. This implies a "fill-up" cost of $\$ 4.63$ for the BEV, which is about $40 \%$ lower than that of the FCV.

\section{Conclusion}

We use widely-cited government studies to directly compare the costs associated with producing and refueling FCVs and BEVs. The analysis is based on an automobile model (similar to a Honda Civic) that is representative of the largest segment of the automobile market. A comparison is important since the government and industry are devoting increasing amounts of resources to the goal of developing a marketable $\mathrm{ZEV}$ and the BEV and the FCV are currently the only feasible alternatives.

We find that government studies indicate that it would be far cheaper, in terms of production and refueling costs, to develop a BEV, even if we do not consider the substantial cost of building and maintaining the hydrogen infrastructure on which the FCV would depend. Specifically, the results show that in an economy based on renewable energy, the FCV requires production of between 2.4 and 2.6 times more energy than a comparable BEV. The FCV propulsion system weighs $43 \%$ more, consumes nearly three-times more space onboard the vehicle for the same power output, and costs approximately 46\% more than the BEV system. Further, the refueling cost of a FCV is nearly threetimes greater. Finally, when we relax the renewable energy assumption, the BEV is still more efficient, cleaner, and vastly less expensive in terms of manufacturing, refueling, and infrastructure investment. 


\section{REFERENCES}

${ }^{1}$ U.S. Environmental Protection Agency, Light-Duty Automotive Technology and Fuel Economy Trends 1975-2001, 2001.

${ }^{2}$ Northeast Advanced Vehicle Consortium (under contract to Defense Advanced Research Projects Agency), Interviews with 44 Global Experts on the Future of Transportation and Fuel Cell Infrastructure and a Fuel Cell Primer, Agreement No. NAVC1099-PG030044, 2000.

${ }^{3}$ General Motors, Argonne National Laboratory, BPAmoco, Exxon Mobile, and Shell, Well-to-Wheels Energy use and Greenhouse Gas Emissions of Advanced Fuel/Vehicle Systems, 2001.

${ }^{4}$ CA Energy Commission and the Air Resource Board, A Fuel Cycle Energy Conversion Efficiency Analysis, 2000.

${ }^{5}$ CA Energy Commission and the Air Resource Board, A Fuel Cycle Energy Conversion Efficiency Analysis, 2000.

${ }^{6}$ U.S. Department of Energy, Annual Progress Report, 2003.

${ }^{7}$ Padro, C., V. Putsche, Survey of Economics of Hydrogen Technologies, National Renewable Energy Laboratory Study NREL/TP-570-27079, 1999.

${ }^{8}$ Arthur D. Little, Inc. report to Department of Energy, Cost Analysis of Fuel Cell System for Transportation, Ref. No. 49739, SFAA No. DESC02-98EE50526, 2001.

${ }^{9}$ AC Propulsion Inc., AC150 GEN-2 EV Power System Specification Document, 2001.

${ }^{10}$ Solectria Corp., DMC0645 AC Motor Controller Specification, 2001.

${ }^{11}$ National Renewable Energy Laboratory, Advanced Battery Readiness Ad Hoc Working Group Meeting Report 2000.

${ }^{12}$ Padro, C., V. Putsche, Survey of Economics of Hydrogen Technologies, National Renewable Energy Laboratory Study NREL/TP-570-27079, 1999.

${ }^{13}$ Cuenca, R., L. Gaines, A. V., Evaluation of Electric Vehicle Production and Operating Costs, Center for Transportation Research, Argonne National Laboratory, 1999.

${ }^{14}$ Gaines, L., R. Cuenca, Costs of Lithium Ion Batteries, Center for Transportation Research, Argonne National Laboratory, 2000.

\section{Notes}


${ }^{1}$ BEVs and FCVs with performance characteristics comparable to these specifications have been developed and tested. For instance, the Honda FCX, recently presented as one of the first commercially available fuel-cell vehicles, has a peak power of $80 \mathrm{HP}$ and a maximum range of 220 miles. In August 2003, using Lithium-ion batteries, AC Propulsion produced a BEV that has a range of 250 miles at speeds of $75-80 \mathrm{mph}$ and goes from $0-60 \mathrm{mph}$ in about 4 seconds.

${ }^{2}$ Studies on EV charging infrastructure in California found that a large number of electric vehicle will not severely tax the existing power grid. In fact, the load leveling effect of the vehicles would be beneficial, see "Electric Vehicle and Energy use Fact Sheet" published by California Air Resources Board, (January 2002).

${ }^{3}$ The actual efficiency would most likely be significantly lower since there are "parasitic" losses from fans, pumps etc. However, since the ADL study did not separately account for parasitic losses in the fuel cell stack and fuel processor, they were conservatively not considered in this study.

${ }^{4}$ The cost per tank is based on the Padro and Putsche [12] estimate of $\$ 6.49$ per $\mathrm{kg}$ to produce the $3.2 \mathrm{~kg}$ of hydrogen necessary to power the FCV for 300 miles and $\$ .055$ cents per $\mathrm{kWh}$ to provide the $77.9 \mathrm{kWh}$ required to power the BEV for 300 miles.

${ }^{5}$ To store $3.2 \mathrm{~kg}$ of hydrogen the tank must be 215 liters [12] .

${ }^{6}$ The BEV has the ability to capture approximately $10 \%$ of the energy sent to the wheels back to the battery pack during deceleration, this is commonly known as regeneration. Accounting for the drivetrain efficiency, and $10 \%$ regeneration, $64.5 \mathrm{kWh}$ must be stored in the battery to deliver $60 \mathrm{kWh}$ to the wheels.

${ }^{7}$ The electric drive train volume with a $66 \%$ packing factor occupies 68 liters for both the FCV and BEV, See AC150 GEN-2 EV Power System Specification Document, [9].

${ }^{8}$ Lithium-ion batteries provide approximately $230 \mathrm{Wh} / 1$; a $43 \%$ packing factor reduced this to $161 \mathrm{Wh} / 1[11]$.

${ }^{9}$ The study reports on a $55 \mathrm{~kW}$ fuel cell, but also indicates that the fuel cell cost scales well with power. 